This is a postprint of the following peer-reviewed publication:

Sterli J, Müller J, Anquetin J, Hilger A. 2010. The parabasisphenoid complex of Mesozoic turtles and the evolution of the testudinate basicranium. Canadian Journal of Earth Sciences 47: 1337-1346.

\title{
The parabasisphenoid complex in Mesozoic turtles and the evolution of the testudinate basicranium
}

\author{
Juliana Sterli1*, Johannes Müller², Jérémy Anquetin³ , André Hilger4
}

1 Museo Paleontológico Egidio Feruglio, Av. Fontana 140, 9100 Trelew, Chubut, Argentina.

${ }^{2}$ Museum für Naturkunde, Leibniz-Institut für Evolutions- und Biodiversitätsforschung an der Humboldt-Universität zu Berlin, Invalidenstr. 43 D-10115 Berlin, Germany.

3UMR CNRS 7207 MNHN UPMC, Muséum National d'Histoire Naturelle, Département Histoire de la Terre, CP 38,8 rue Buffon, 75231 Paris cedex 05, France.

4Helmholtz-Zentrum für Materialien und Energie, Hahn-Meitner-Platz 1, 14109 Berlin, Germany.

*Corresponding author: jsterli@mef.org.ar

\begin{abstract}
During early development of turtles and other amniotes, the parabasisphenoid, or basisphenoid s.l., is formed by at least two centers of ossification: the endochondral basisphenoid s.s. and the dermal parasphenoid. This fusion is usually so dramatic that the two elements cannot be distinguished from each other in the adult stage. Here we describe the basicranium of two individuals of Mesozoic turtles from Europe, Plesiochelys etalloni and Pleurosternon bullockii, partly using micro-CT scans, and show that in both taxa para- and basisphenoid remain distinguishable throughout life. We also identify the extent that each of the two elements has contributed to the formation of the braincase floor. Because the structure of the parabasisphenoid determines the course of the internal carotid artery into the skull, our findings allow us to discuss the early evolution of the carotid pattern and the turtle basicranium in new detail. By surveying the main patterns of carotid circulation in extinct and extant turtles, we bring new evidence to the idea that it was largely the ossification of the parasphenoid which, along with the closure of the interpterygoid vacuity and the posterior extension of the pterygoids, shaped the internal carotid patterns as seen in modern turtles.
\end{abstract}




\section{INTRODUCTION}

Embryological evidence suggests that, similarly to other amniotes, the parabasisphenoid (basisphenoid s.I.) of extant turtles is composed of a synostosial fusion of an endochondral bone (basisphenoid s.s.) and a dermal bone (parasphenoid) (Pehrson 1945; Bellairs and Kamal 1981; Gaffney 1979a and literature cited therein; Sheil 2003). In adult turtles, both bones cannot be differentiated from each other because they fuse very early in ontogeny. Until now no fossil turtles have been described in which these two bones are distinguishable one from each other.

The morphology of the para- and basisphenoid also has implications for the course of the internal carotid artery. Generally in tetrapods, the internal carotid artery enters the braincase posteriorly and becomes subdivided at the anterior level of the basicranium into a palatal and cerebral branch, with the former continuing to the snout and the latter entering the hypophyseal fossa (Shishkin 1968). In several living taxa (e.g., squamates, crocodiles, turtles), embryological studies show that the ossification of the parasphenoid traps the carotid artery between this bone and the basisphenoid s.s. (Shishkin 1968; Rieppel 1993). In modern turtles, the carotid artery is enclosed inside the canalis caroticus internus either within the pterygoid or between the pterygoid and the parabasisphenoid in cryptodiran turtles, or between the prootic and parabasisphenoid or prootic-quadrate in pleurodiran turtles, and the separation into cerebral and palatal branch occurs inside the pterygoid-braincase complex. However, extinct turtles show that the diversity of carotid circulation patterns is far more complex than previously thought. In a recent study, Sterli and de la Fuente (2010) described six different patterns of relationship between the pterygoid, the braincase, and the carotid artery in fossil and extant turtles, indicating that the morphological diversity as seen in modern taxa is not representative of turtles as a whole, and that fossil taxa can provide valuable information about the evolution of this unique anatomical structure.

The main objective of the present work is to describe the parabasisphenoid complex of two Mesozoic turtles, Plesiochelys etalloni and Pleurosternon bullockii, partially using micro-CT scans. We also clarify problematic and previously unknown details about the course of the internal carotid artery in these taxa, and show that both species largely have a distinguishable para- and basisphenoid in adults, an unusual condition in turtles. Furthermore, we will show that the presence of these bones in the two investigated taxa has implications for the evolution of the parabasisphenoid complex in turtles and its involvement in the enclosure of the carotid artery as proposed by Sterli and de la Fuente (2010).

Institutional abbreviations: $\mathrm{MH}$ : Naturhistorisches Museum, Basel, Switzerland; PMZH, Palaeontological Museum, University of Zürich, Switzerland; SM, Städtisches Museum, Solothurn, Switzerland; UMZC, University Museum of Zoology, Cambridge, U.K.

Anatomical abbreviations: ac, arteria cerebralis; ane, apertura narium externa; ani, apertura narium interna; ap, arteria palatina in canalis caroticus lateralis; bs, basisphenoid; bo, basioccipital; caj, cavum acusticojugulare; cc, cavum cranii; cci, canalis caroticus internus; ccv, canalis cavernosus; cl, cavum labyrinthicum; cna, canalis nervi abducentis; col, columella; csa, canalis semicircularis anterior; cst, canalis stapedio-temporalis; ct, cavum tympani; ex, exoccipital; fccp, foramen carotici cerebralis posterior; fcl, foramen caroticum laterale; fn, fossa nasalis; fnv, foramen nervi vidiani; fp, foramen prooticum; fpcci, foramen posterius canalis carotici interni; fpp, foramen palatinum posterius; fr, frontal; ju, jugal; mx, maxilla; na, nasal; nc, notochord crest; op, opisthotic; pa, parietal; pal, palatine; pbs, parabasisphenoid; pc, processus clinoideus; pi, processus interfenestralis of opisthotic; pip, processus inferior parietalis; pmx, premaxilla; po, postorbital; ppe, processus pterygoideus externus; prf, prefrontal; pro, prootic; ps, parasphenoid; pt, pterygoid; qj, quadratojugal; qu, quadrate; rst, recessus scalae tympani; so, supraoccipital; sq, squamosal; vo, vomer.

\section{MATERIALS AND METHODS}

The specific description of the parabasisphenoid complex in turtles is based on two specimens belonging to two different species of fossil turtles, Plesiochelys etalloni from the Upper Jurassic of Switzerland and Pleurosternon bullockii from the Lower Cretaceous of England. Both species are considered stem-Cryptodira (Gaffney et al. 2007; Joyce 2007). The systematic position of the genus Plesiochelys is somewhat problematic, but Gaffney (1975a) recognized two valid species based on cranial anatomy: Plesiochelys etalloni and P. planiceps. Based on several specimens (SM 134, SM 135, SM 594, and $\mathrm{MH}$ 435), Gaffney (1976) described in detail the skull anatomy of Plesiochelys etalloni and pointed out that the pterygoid and the braincase have a large sutural contact, resulting in a complete enclosure of the internal carotid artery after the latter enters the skull in the posteroventral part of the pterygoid. In contrast, Rieppel (1980: 127), based on several specimens of $P$. etalloni (SM 134 and 136) and "Thalassemys" moseri (PMZH A/III 514), suggested that the flooring of the canalis caroticus 


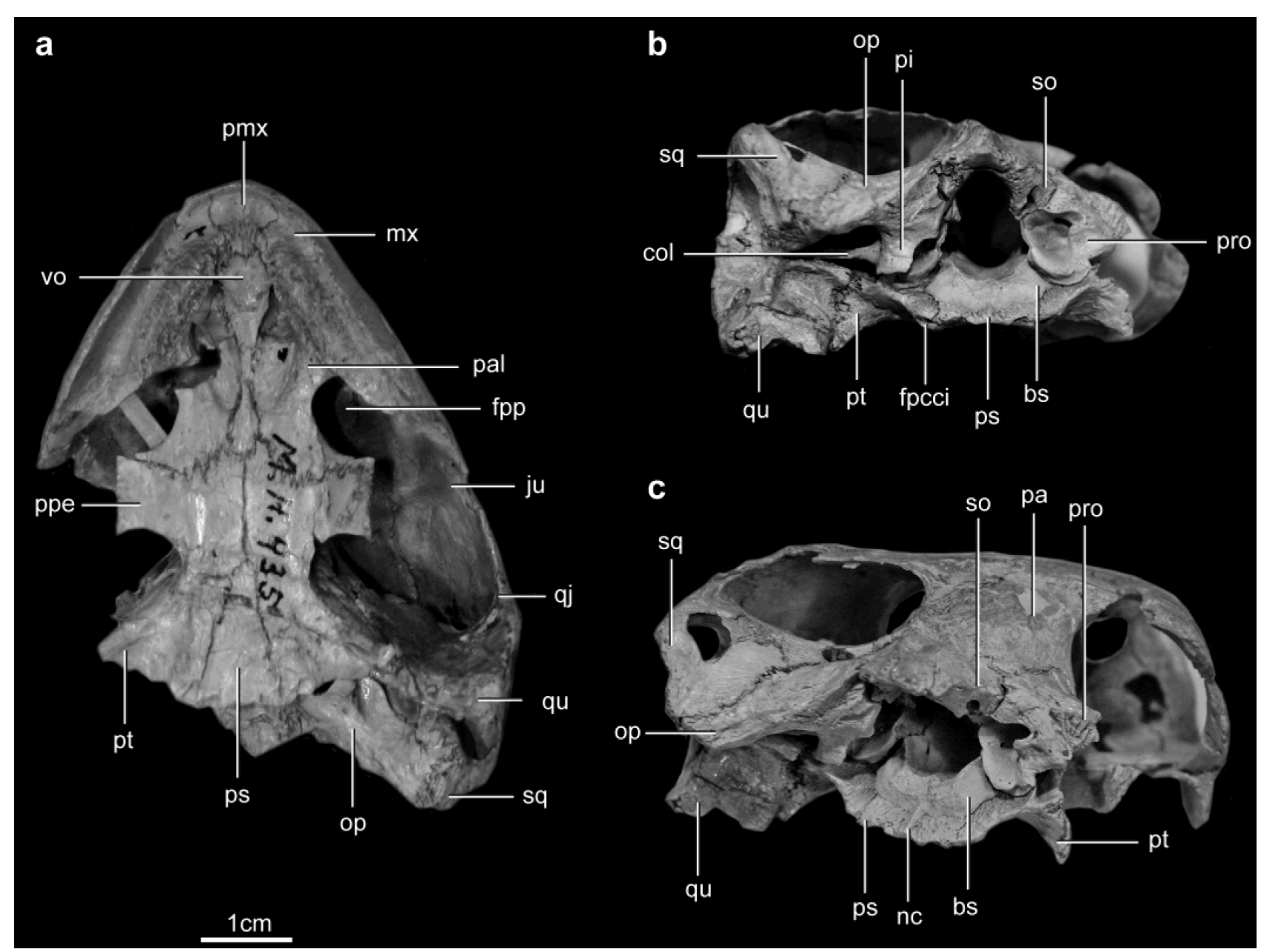

Figure 1 - Photographs of the skull of Plesiochelys etalloni (MH 435). (a) Ventral view. (b) Posterior view. (c) Right lateroposterodorsal view. See "Anatomical abbreviations" section in text.

internus in not complete in these species, representing a morphocline between the condition found in baenids and crown-group cryptodires. However, this discussion is mostly irrelevant for the present study and simply suggests that there may be some variability in the extent of the flooring of the canalis caroticus internus in stem cryptodires.

The other species discussed in this paper is Pleurosternon bullockii. The skull restudied here, UMZC T1041, was originally described as a new genus and species, Mesochelys durlstonensis, by Evans and Kemp (1975). Later, Gaffney (1985) and then Gaffney and Meylan (1988) synonymized Mesochelys durlstonensis with Pleurosternon bullockii. Most subsequent authors (e.g., Milner 2004), including ourselves, follow this proposal.

High-resolution X-ray micro-computed tomography was applied to obtain detailed information on the braincase of Plesiochelys etalloni ( $\mathrm{MH} 435)$. The scan was performed at the Helmholtz-Zentrum Berlin für Materialien und Energie, with 1000 projections over $360^{\circ}$, an exposure time of $0.6 \mathrm{sec}$, a voltage of $100.0 \mathrm{kV}$, and a current of $100 \mu \mathrm{A}$.

\section{DESCRIPTION}

Although in the last years many new fossil turtles were found and new patterns of carotid circulation were described (summarized in Sterli and de la Fuente 2010), some confusion remains regarding the nomenclature of the foramina serving for the passage of the carotid artery and its branches. Therefore, we would like to standardize the nomenclature regarding the foramina involved in carotid circulation in turtles in order to be precise, clear, and avoid misinterpretation about the primary homology statements regarding these structures.

Foramen posterius canalis carotici interni (fpcci): The posterior entrance into the braincase of the internal carotid artery (Gaffney 1979a). The internal carotid artery anteriorly bifurcates into the cerebral and palatine arteries (or branches). This bifurcation may be closed ventrally by bone or not (see Discussion and Conclusion). 

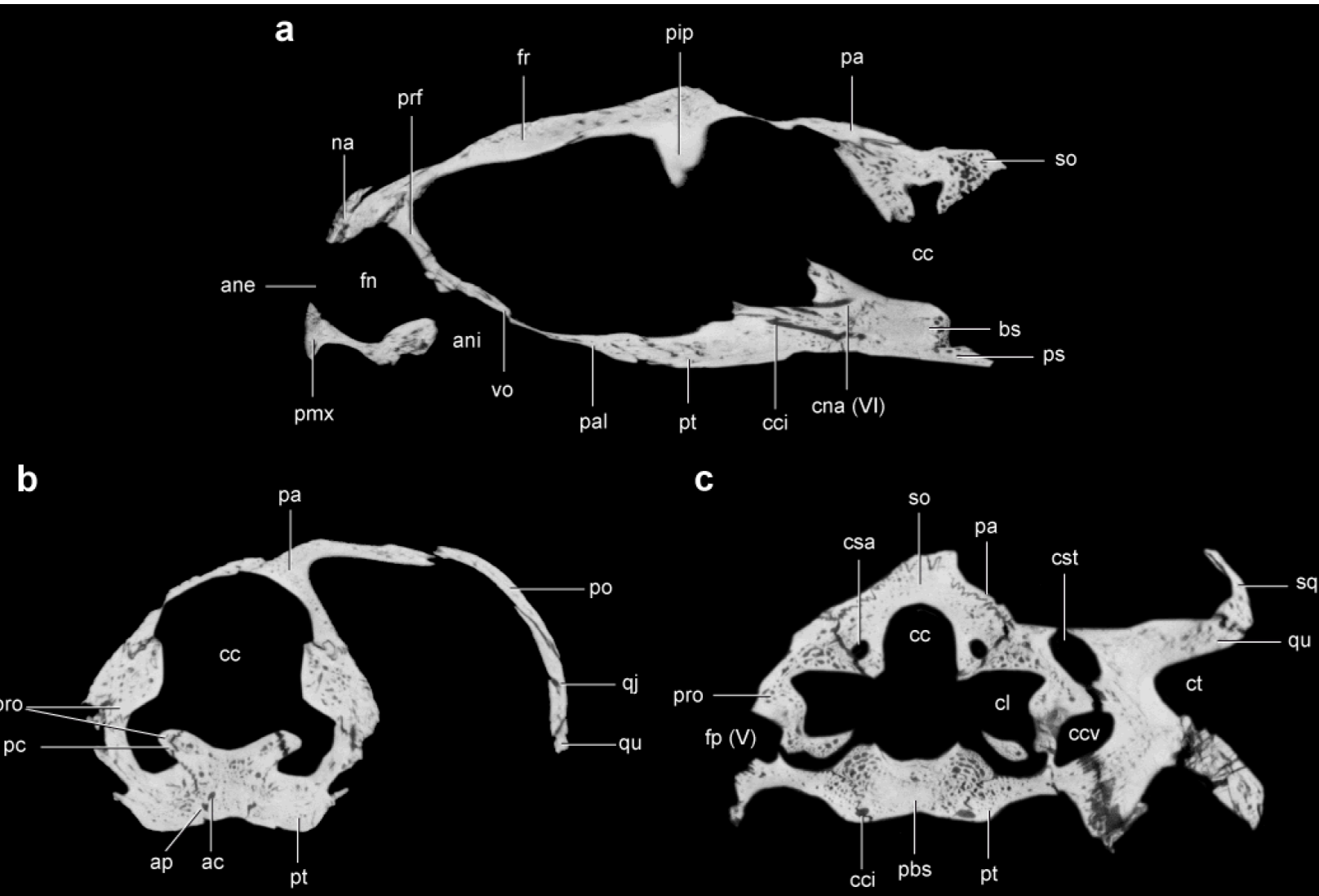

d

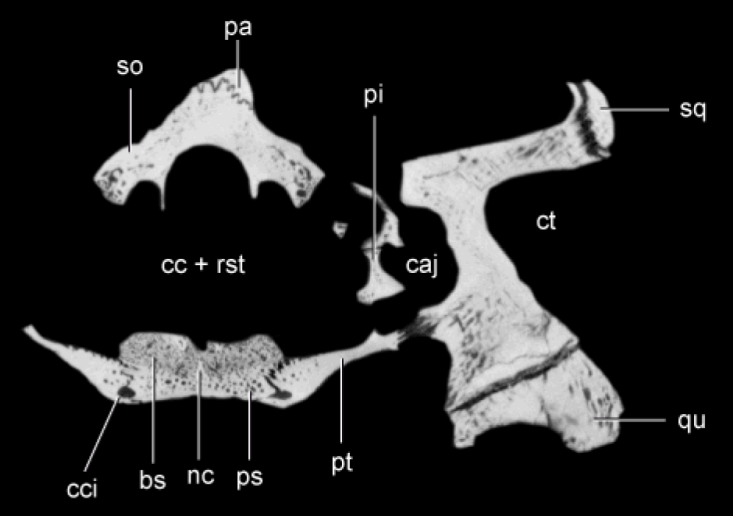

e

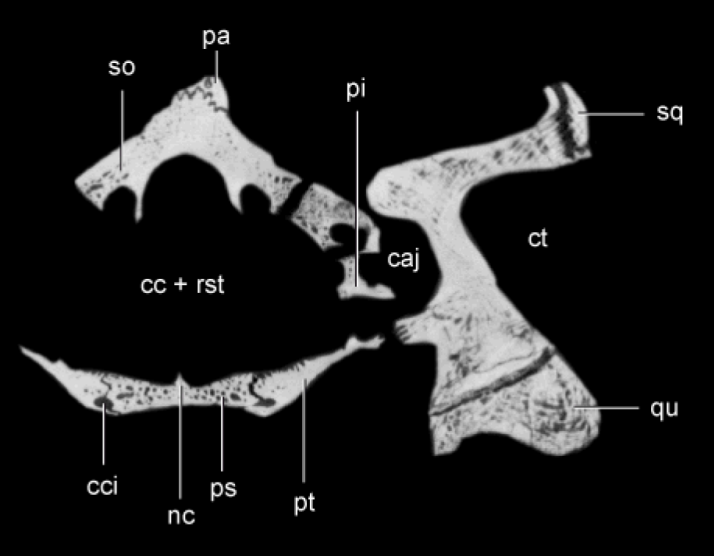

Figure 2 - Micro CT scan of the skull of Plesiochelys etalloni (MH 435). (a) yz slide (number 895 of 1650) near the sagital plane. (b) xy slide (number 1313 of 1991). (c) xy slide (number 1517 of 1991). (d) xy slide (number 1573 of 1991). (e) xy slide (number 1587 of 1991 ). See "Anatomical abbreviations" section in text.

Foramen carotici cerebralis posterior (fccp): The posterior entrance into the braincase of the cerebral branch of the internal carotid artery (modified from Rieppel, 1980). When the bifurcation of the internal carotid artery is not covered ventrally by bone this foramen is clearly seen on the ventral surface of the basisphenoid. We claim for the usage of this name to avoid the confusion with the commonly used term foramen caroticum basisphenoidale. This foramen has been first defined by Gaffney (1983: 448) in its description of the cranial anatomy of Meiolania platyceps as "a large opening of the canalis [caroticus internus] that communicates with the space formed by the intrapterygoid slit. The homologue of this opening is not obvious [...]. [...] it is most likely that the foramen caroticum basisphenoidale contained the palatine artery [...]." Hence, following the reasonable interpretation of Gaffney (1983), the palatine branch of the internal carotid exits the canalis caroticus internus through the foramen caroticum basisphenoidale and continues forward ventral to the parabasisphenoid and through the intrapterygoid slit in M. platyceps. For the moment, this pattern is known 
only in meiolaniids (see Discussion and Conclusion). After Gaffney (1983), the name foramen caroticum basisphenoidale has been mistakenly applied by most authors to the foramen through which the cerebral branch of the internal carotid enters the skull (foramen carotici cerebralis posterior).

Foramen carotici cerebralis anterior (fcca): The anterior opening of the cerebral artery after its path through the basisphenoid (redefinition of the foramen anterior canalis carotici interni of Gaffney 1979a). This foramen is usually located in the posterior wall of the sella turcica (Gaffney 1979a).

Foramen caroticum laterale $(\mathbf{f c l})$ : The posterior opening for the entrance of the palatine artery (lateral branch of the internal carotid artery after bifurcation) into the skull (Gaffney 1979a). In basal turtles where the interpterygoid vacuity is still open, the palatine artery would have entered the skull through this open space; in more derived turtles it usually pierces the pterygoid.

\section{Plesiochelys etalloni (MH 435)}

External view-As this species was described in detail by Gaffney (1976), we only describe the parabasisphenoid complex and associated structures of specimen $\mathrm{MH} 435$. Because the posterior part of the skull is missing in specimen $\mathrm{MH}$ 435, the cavum cranii and associated structures are easily visible. Whereas in ventral view it seems that the parabasisphenoid is formed by only one bone (Fig. 1a), the perception changes when the specimen is seen in dorsal and posterior view (Figs. 1c, 1d) and it becomes evident that the parabasisphenoid complex is actually formed by two fused bones, distinguishable one from the other in shape and structure. The dorsal element is the thicker of the two and quadrangular in shape, while the ventral element is notably thinner, narrower, and extends more posteriorly than the dorsal one. We interpret the dorsal element to be the endochondral basisphenoid, and consider the ventral element to be the dermal parasphenoid. The basisphenoid also contacts the pterygoid and the prootic laterally. The parasphenoid extends posteriorly together with both pterygoids. Posterodorsally, the parasphenoid has a roughened area, which is the contact surface with the basioccipital. Furthermore, in the midline of the dorsal surface of the parasphenoid there is a distinct crest, which can be considered the imprint of a groove in the basisphenoid (Figs. 1c, 2 d, 2e). It is well known that in the early ontogeny of extant turtles the notochord inscribes a narrow notochordal canal that extends into the ventral surface of the basal plate where the basisphenoid ossifies (Sheil 2005; Sheil and Greenbaum 2005). At stage 24 in Apalone spinifera, Sheil (2003) describes that the 'basisphenoid is incised by a prominent notochordal groove that extends anteriorly to the midbody of the element'. We therefore interpret the groove in the basisphenoid and the corresponding crest in the parasphenoid to represent the remainder of the notochordal canal that was trapped between both bones during development.

Internal view-Specimen $\mathrm{MH} 435$ was scanned using micro-CT technology (Figs. 2a-e). Based on the anteroposterior slices a clear distinction between paraand basisphenoid can be observed in the posteriormost area (Figs. 2d-e). As was noticed by Gaffney (1976), the posterior opening of the canalis caroticus internus is located far posterior in the pterygoid- parabasisphenoid suture (Figs. 2a-e), and further anteriorly the canalis caroticus internus runs between the parasphenoid and the pterygoid (Figs. 2c-e). More anteriorly, where the arteria carotica interna splits into its cerebralis and palatina portions, the canalis carotici interni is located deeply in the undifferentiated parabasisphenoid (Fig. 2b). As described below, the parasphenoid traps the internal carotid artery between the parasphenoid and basisphenoid anteriorly (Figs. 2a-e).

\section{Pleurosternon bullockii (UMZC T1041)}

In ventral and dorsal view the endochondral basisphenoid and the dermal parasphenoid can be clearly distinguished from each other (Figs. 3a-c). The basisphenoid is a thick quadrangular element, but not as thick as in Proganochelys quenstedti or Palaeochersis talampayensis (pers. obs. JS). The parasphenoid lies ventral to the basisphenoid. It is narrower and longer than the basisphenoid, contacting the basioccipital posterodorsally and the pterygoid laterally. The anterior contact of the parasphenoid with the palatal bones cannot be described because the palatines and the posterior part of the vomer are missing. Similarly to $\mathrm{MH}$ 435 (see above) there are differences in the texture of both bones, so it seems that the parasphenoid is a denser bone than the basisphenoid.

In the original description of Mesochelys durlstonensis Evans and Kemp (1975) recognized that UMZC 1041 has a basitrabecular (basipterygoid) process that fits into the pterygoid and that the foramen that 'opens into the pit for reception of the basipterygoid process' is probably the posterior opening of the canalis nervi vidiani. They also pointed out that the 'foramen posterior canalis carotici interni is on the ventro-lateral margin of the basisphenoid at about mid-length, alongside the basipterygoid process'. Gaffney (1979b) found a similar structure in Glyptops plicatulus and noted that this structure is not the basitrabecular process. Consequently, there is no 


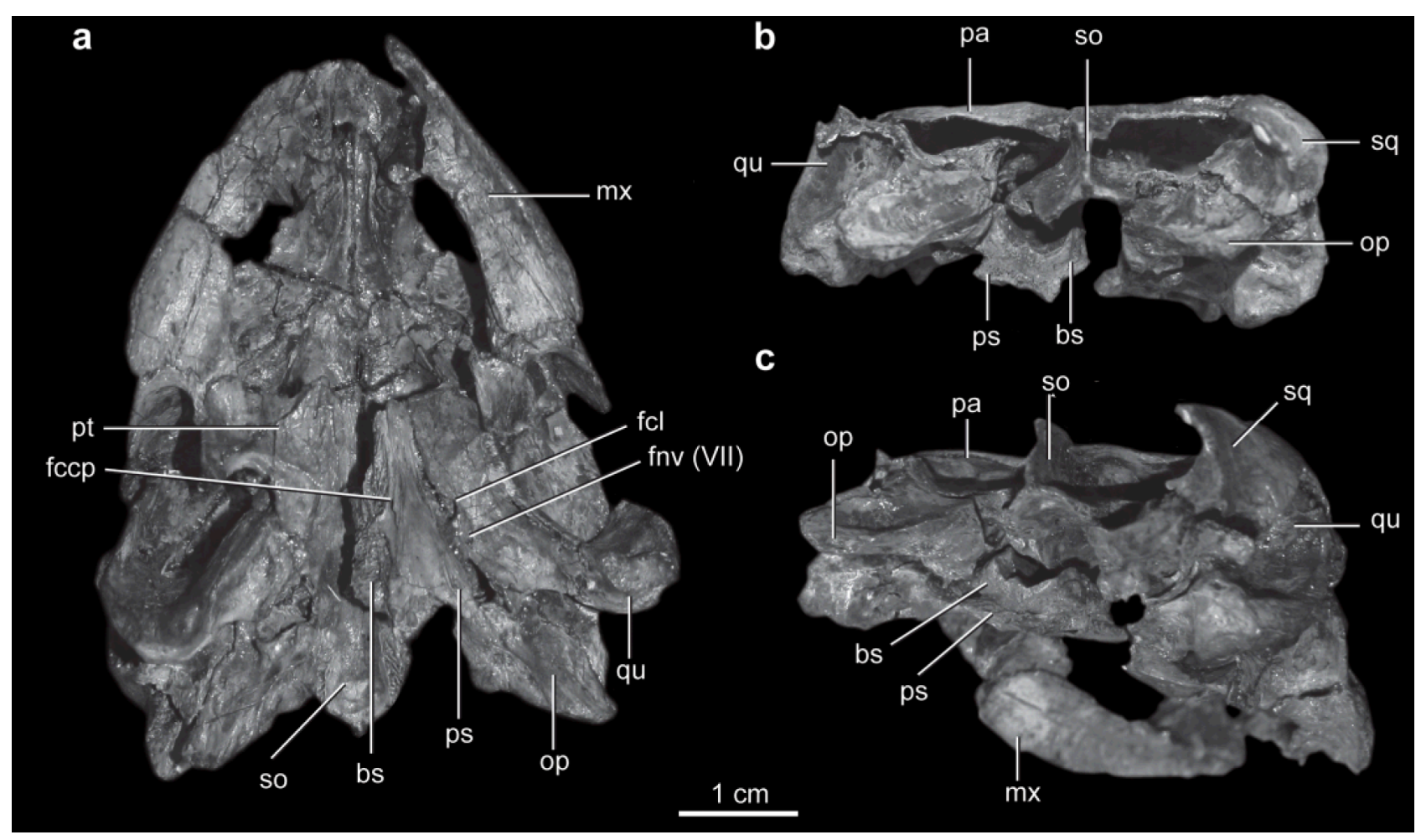

Figure 3 - Photographs of the skull of Pleurosternon bullockii (UMZC 1041). (a) Ventral view. (b) Posterior view. (c) Right lateroposteroventral view. See "Anatomical abbreviations" section in text.

processus basitrabecularis in Glyptops plicatulus or in Pleurosternon bullockii, but a sinus where some structures can be recognized (see below). We agree with Gaffney's interpretation, because it can be well seen that in Pleurosternon bullockii there is no process going down and fitting on the pterygoid as in Proganochelys quenstedti, Palaeochersis talampayensis, and Kayentachelys aprix. Besides, it is clearly seen that the parabasisphenoid complex and the pterygoid of Pleurosternon bullockii are at the same level, in contrast to the lower position of the pterygoid in the above mentioned basal turtles. In addition, in topological terms the basitrabecular process of basal turtles (e.g., Pr. quenstedti, K. aprix) is located well anteriorly to the posterior foramen for the cerebral artery (foramen carotici cerebralis posterior), consequently the bifurcation between the cerebral and palatine branches of the internal carotid would have been far posteriorly to the basitrabecular process. The position and the structures involved in the basitrabecular process of basal turtles and the sinus in the parabasisphenoid complex of Pleurosternon bullockii do not seem to satisfy the primary homology assessment. Instead of a basitrabecular process in Pleurosteron bullockii there is a concavity leading to two foramina, interpreted by Evans and Kemp (1975) as the foramen posterior canalis carotici interni (the medial one located in the basisphenoid) and the posterior foramen pro ramo nervi vidiani (the lateral one in the pterygoid) (Fig. 3a). Based on comparisons of Pleurosternon bullocki with other fossil turtles such as Glyptops plicatulus, Boremys pulchra, Dracochelys bicuspis, Kallokibotion bajazidi, we reinterpret the medial foramen located in the basisphenoid as the posterior foramen for the cerebral artery (foramen carotici cerebralis posterior) through which the arteria cerebralis enters the skull and consider the lateral foramen located in the pterygoid as the foramen caroticum laterale through which the arteria palatina enters the skull (Fig. 3a). In this species the bifurcation between the palatine and cerebral arteries is not floored by bone, resembling the morphology found in Glyptops plicatulus as suggested by Gaffney (1979b). We agree with Evans and Kemp (1975) that the small foramen located in the ventral side of the pterygoid 'behind and lateral to the basispterygoid articulation' could be the foramen pro ramo nervi vidiani (Fig. 3a), as in Glyptops plicatulus (Gaffney 1979b). The foramen pro ramo nervi vidiani is the posterior opening to a short canal connecting the canalis caroticus interni and the canalis cavernosus and transmits the palatine branch of nerve VII and a small branch of the internal carotid artery (Gaffney 1979a). In Pleurosternon bullockii as in Glyptops plicatulus, the canalis caroticus internus is not completely floored by bone consequently, the foramen pro ramo nervi vidiani is seen in the ventral view of the pterygoid. 


\section{DISCUSSION AND CONCLUSION}

Among extant amniotes, the presence of at least two separate ossification centers in the anteroventral region of the basicranium (basisphenoid and parasphenoid) have been documented during the embryological development of turtles, birds, crocodiles, and squamates (de Beer 1937; Pehrson 1945; Jollie 1957; Bellairs and Kamal 1981; Klembara 1993; Rieppel 1993 and references therein). Later in ontogeny, both bones fuse and become undistinguishable in the adults. However, there are a few cases in the fossil record where the parasphenoid and basisphenoid can be distinguished from each other. The best-studied clade where the parasphenoid and basisphenoid are well differentiated is the Sauropterygia. In this group, the morphology and relationship between these bones and the interpterygoid vacuity, the pterygoids, and the basioccipital are phylogenetically informative characters (O'Keefe 2001). Among archosauromorphs, a separate parasphenoid and basisphenoid were recognized in the crocodylomorph Stratiosuchus maxhechti from the Upper Cretaceous of Brazil (Gonçalves 2003). Among Parareptilia, a clear suture between the parasphenoid and basisphenoid was described in the procolophonid Eumetabolodon bathycephalus from the Lower Triassic of China (Ling 1983). The remaining fossil taxa in which the two bones can be identified are the two fossil turtles described in this study.

The close relationship between the parasphenoid, basisphenoid, and the entrance and circulation of the carotid artery provide important insights into the evolution of the carotid circulation in turtles. Moreover, the description of a distinguishable parasphenoid and basisphenoid in two species of fossil turtles enables us to discuss the evolution of the internal carotid complex in turtles within a phylogenetic context. As pointed out by Sterli and de la Fuente (2010) the evolution of the carotid circulation in turtles is far more complex than previously thought, and the authors described six different patterns of carotid circulation. In the following paragraphs we expand the ideas presented by Sterli and de la Fuente (2010) about the correlation between the more extensive ossification of the parasphenoid and the enclosure of the internal carotid in bone in turtles.

In Proganochelys quenstedti, the most basal turtle for which this anatomical area is known, the interpterygoid vacuity is open and the parabasisphenoid is pierced by paired foramina (foramen carotici cerebralis posterior; Fig. 4a). These foramina are located relatively close to the midline and serve as the entrance for the arteria cerebralis (Gaffney 1983, 1990). The arteria palatina is interpreted to continue anteriorly through the interpterygoid vacuity (Gaffney and Meylan 1992). This condition is also known in Kayentachelys aprix (Fig. 4b), Heckerochelys romani, and Condorchelys antiqua and is recognized as pattern VI by Sterli and de la Fuente (2010). In this configuration, the bifurcation of the internal carotid artery into its palatine and cerebral branches is not enclosed by bone. Gaffney and Meylan (1992: 17) suggested that an intermediate morphology between the aforementioned arrangement and the patterns seen in more derived turtles may be present in Kallokibotion bajazidi. In Kallokibotion bajazidi, as well as in Mongolochelys efremovi, the interpterygoid vacuity is closed and the arteria palatina penetrates the basicranium through paired foramina caroticum laterale, located anteriorly close to the parabasisphenoidpterygoid suture (Fig. 4c). In these species, two pairs of foramina are visible in ventral view: the foramen caroticum laterale anteriorly and the foramen carotici cerebralis posterior posteriorly (pattern $\mathrm{V}$ of Sterli and de la Fuente 2010). The bifurcation of the internal carotid into the palatine and cerebral branches occurs outside and ventral to the bone. In all of the aforementioned species, the internal carotid, or its branches, is not trapped between the basisphenoid and parasphenoid by a posteroventral expansion of the latter. However, the more expanded ossification of the parasphenoid and pterygoid starts to close the interpterygoid vacuity in Kallokibotion bajazidi and Mongolochelys efremovi, reducing the entrance of the palatine artery to a foramen.

In Meiolaniidae, the pattern of internal carotid circulation is difficult to interpret. Because the pterygoid forms a canalis caroticus internus posterolaterally and the foramen posterius canalis carotici interni opens well posteriorly in the pterygoid, Gaffney $(1983,1996)$ proposed that the morphology of meiolaniids was similar to that of eucrytodires. However, anterior to the parabasisphenoid-pterygoid suture, the canalis caroticus internus is not floored by bone (= foramen caroticum basisphenoidale sensu Gaffney 1983) and the palatine branch of the internal carotid is interpreted to branch off there, continue forward ventral to the bone, and enter

Figure 4 (next page) - Evolution of the internal carotid complex in turtles. (a-f) morphology of the basicranium in selected turtles (ventral view). (g-h) evolution of character states according to Gaffney et al. (2007) and Joyce (2007), respectively. (a) Proganochelys quenstedti (redrawn from Gaffney 1990). (b) Kayentachelys aprix (redrawn from Sterli and Joyce 2007). (c) Mongolochelys efremovi (redrawn from Sukhanov 2000). (d) Meiolania platyceps (redrawn from Gaffney 1983; ventral part of left pterygoid reconstructed to show the intrapterygoid slit). (e) Notoemys laticentralis (redrawn from Lapparent de Broin et al. 2007). (f) Sinemys gamera (redrawn from Brinkman and Peng 1993). Dark gray: internal carotid artery and cerebral branch. Light gray: palatine branch. Dashed line: path of the arteries covered by bone. Continuous line: path of the arteries not surrounded by bone. See "Anatomical abbreviations" section in text. 

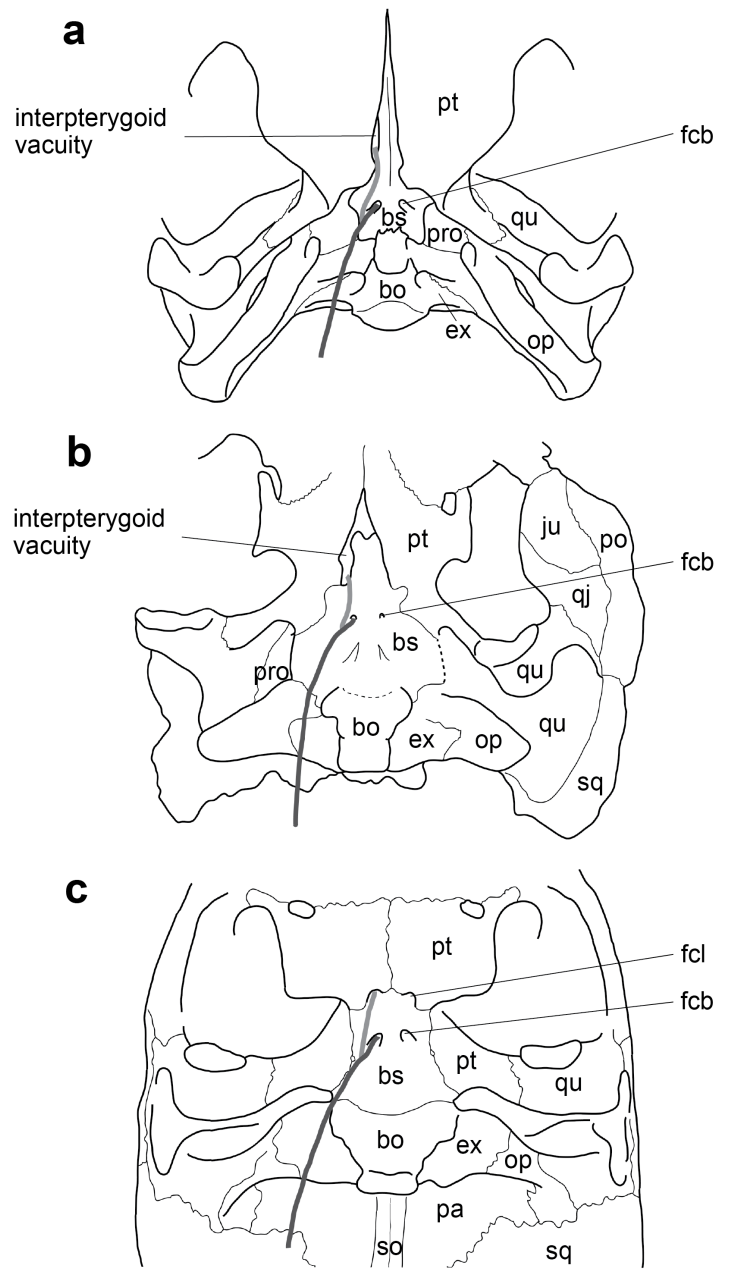

d

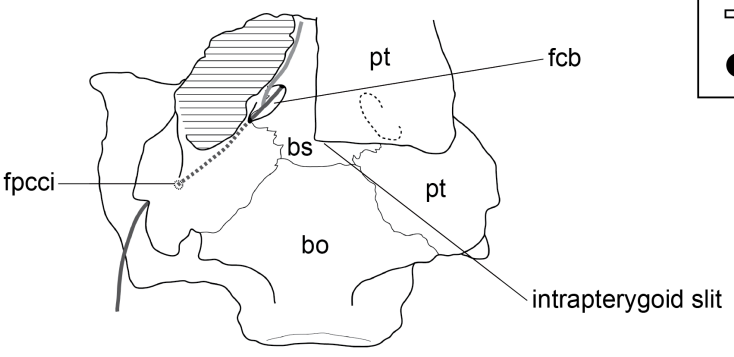

(1) interpterygoid vacuity partially or completely closed

(2) expansion of parasphenoid ventral to basisphenoid

(3) posterior extension of pterygoid

- acquisition

reversal

crown-group turtles (Testudines)

e

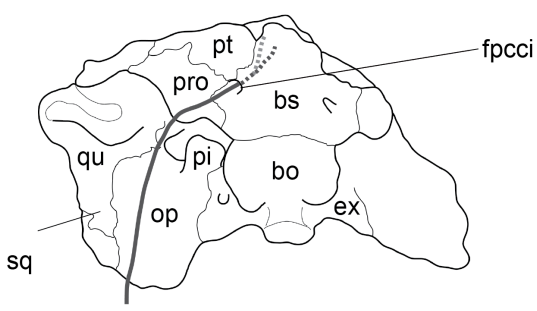

$\mathbf{f}$

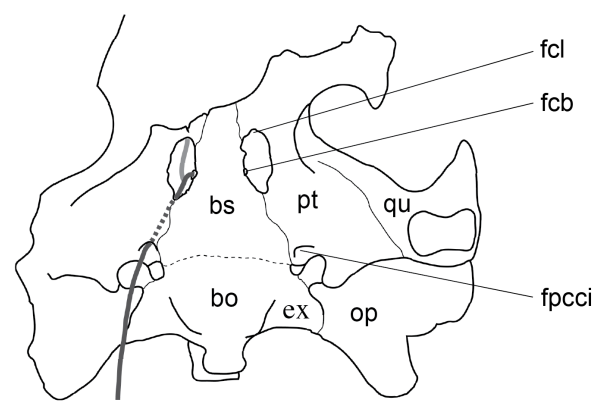

Proganochelys

Australochelys

Palaeochersis

Proterochersis

Megapleurodira

(1)

Kayentachelys

Mongolochelys

Kallokibotion

Pleurosternidae

Baenidae

Solnhofia

Plesiochelyidae

Xinjiangchelys

(3)
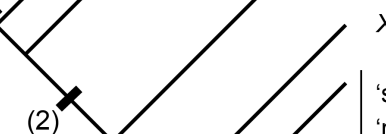

'sinemyds'

'macrobaenids'

crown-group cryptodires

Chubutemys

Otwayemys

Meiolaniidae

Proganochelys

Palaeochersis

Australochelys

Proterochersis

Kayentachelys

Meiolania

Mongolochelys

Kallokibotion

Notoemys

Pleurodira

Pleurosternidae

Baenidae

Plesiochelys

(3)

(3)

(2)

Solnhofia

'Thalassemys'

Xinjiangchelys

'sinemyds'

'macrobaenids'

crown-group cryptodires 
the skull through the intrapterygoid slit (Fig. 4d). The cerebral artery enters the skull in the basisphenoid through the foramen carotici cerebralis posterior. The intrapterygoid slit, a structure unique to meiolaniids, is formed by expansions of the pterygoids that form a horizontal sheet of bone ventral to the basisphenoid (Gaffney, 1983). Primary homology assessment is particularly difficult concerning this structure. Actually, in the current state of knowledge, this morphology could be argued to derive from the eucryptodire condition, as suggested by Gaffney (1996), or from the pattern seen in the most basal turtles, in which case the intrapterygoid slit would be a modified interpterygoid vacuity. Hence, it is unclear whether or not the parasphenoid expands ventrally to the basisphenoid in meiolaniids. As for eucryptodires (see below), this issue should be further investigated.

In Notoemys laticentralis, the most basal stem pleurodire in which this area is known, the split between the cerebral and palatine branches and the part of the internal carotid artery posterior to that split are floored by bone (Fig. 4e). The foramen posterius canalis carotici interni (fpcci) is formed by the parabasisphenoid and located close to the basisphenoid-prootic suture (Lapparent de Broin et al., 2007). In more derived pleurodires, the foramen posterius canalis carotici interni (fpcci) is formed by the prootic and/or the parabasisphenoid (Gaffney 1979a; pattern III of Sterli and de la Fuente 2010). Given the results presented herein, it can be proposed that the parasphenoid expands ventral to the basisphenoid and traps the internal carotid and its bifurcation into the cerebral and palatine branches in these turtles. The result is the formation of a proper foramen posterius canalis carotici interni (fpcci) that is located more laterally and posteriorly than the foramen carotici cerebralis posterior of more basal taxa. A similar process can be proposed for Paracryptodira: the parasphenoid expands and traps the internal carotid ventral to the basisphenoid up to a point situated midway along the basisphenoid-pterygoid suture (pattern II of Sterli and de la Fuente 2010). As is illustrated herein by UMZC T1041, the bifurcation of the internal carotid into its cerebral and palatine branches is not covered ventrally by bone in Pleurosternon bullockii but rather is contained in a shallow cavity along the basisphenoid-pterygoid suture, as in Glyptops plicatulus (Gaffney 1979b). This could be interpreted as a slightly less developed expansion of the parasphenoid in these forms in comparison to Baenidae, but until the morphology of this area in the latter clade is further investigated no definitive interpretation can be proposed.

In eucryptodires, the pterygoid also forms part of the canalis caroticus internus and the foramen posterius canalis carotici interni (fpcci) opens posteriorly in this bone (pattern I of Sterli and de la Fuente 2010). Some kind of variability seems to exist in the extent to which the pterygoid floors the canalis caroticus internus in stem cryptodires (Rieppel 1980). Similarly, many stem cryptodires ('sinemyds' and 'macrobaenids', pattern IV of Sterli and de la Fuente 2010) show variably developed openings on the ventral surface of the parabasisphenoid that reveal the split of the internal carotid into its cerebral and palatine branches (e.g., Brinkman and Nicholls 1993; Jamniczky et al., 2006; Fig. 4f). According to the results presented above, this can be interpreted as a variable extent of the ossification of the parasphenoid ventral to the basisphenoid. The recently described Basilochelys macrobios (Tong et al. 2009) shows that this variability still exists in early crown-group cryptodires. The evolution of the internal carotid system in fossil eucryptodires is still poorly understood and requires more detailed investigation.

It appears from the previous discussion that three factors can explain the different patterns of internal carotid circulation in turtles: (1) the closure of the interpterygoid vacuity; (2) the expansion of the parasphenoid ventral to the basisphenoid; (3) the posterior extension of the pterygoid alongside the basisphenoid. We mapped these transitions onto two recently proposed turtle phylogenies (Figs. $4 \mathrm{~g}, 4 \mathrm{~h}$ ): that of Gaffney et al. (2007), which represents the continuing work of E. S. Gaffney and collaborators since the late 1970's, and that of Joyce (2007), which supports a partly divergent pattern where some key taxa, previously considered to belong to the crown-group, are placed along the phylogenetic stem of turtles. In the context of the phylogeny of Gaffney et al. (2007), the posterior extension of the pterygoid alongside the basisphenoid is the only one of the three aforementioned features that would evolve once (Fig. 4g). Actually, since Gaffney and Meylan (1988), the posterior extension of the pterygoid is considered an important synapomorphy of Selmacryptodira (i.e., all cryptodires to the exception of Kayentachelys aprix, in that context). The closure of the interpterygoid vacuity would occur twice: along the branch that leads to total group Pleurodira (condition unknown in Proterochersis robusta) and as a synapomorphy of the clade uniting all cryptodires more derived than Kayentachelys aprix. The expansion of the parasphenoid ventral to the basisphenoid would occur three times: as synapomorphies of total group Pleurodira (condition unknown in Proterochersis robusta), Paracryptodira and eucryptodires respectively (the condition in meiolaniids is considered to be unknown for the purpose of this study). The repartition of this character state could also be explained by an acquisition 
along the branch that leads to the clade uniting Kallokibotion bajazidi, Paracryptodira and eucryptodires with a subsequent reversal in $K$. bajazidi. Either way, it involves a three steps process. In the context of the phylogeny proposed by Joyce (2007), the closure of the interpterygoid vacuity and the posterior expansion of the parasphenoid ventral to the basisphenoid would occur only once (Fig. 4h): as synapomorphies of the clade uniting all turtles more derived than Kayentachelys aprix and of Testudines (i.e., the crown-group turtles), respectively. The posterior extension of the pterygoid would be acquired once as a synapomorphy of all turtles more derived than Kayentachelys aprix, and subsequently would have become lost along the branch that leads to total group Pleurodira.

This comparison suggests that the repartition of character states gives stronger support to the phylogeny of Joyce (2007): four changes are required to explain this repartition, whereas six changes are necessary in the context of the phylogeny of Gaffney et al. (2007). Although the difference is not major, it could be additionally argued that the multiple closures of the interpterygoid vacuity (twice) and expansions of the parasphenoid ventral to the basisphenoid (three times or twice with one reversal) necessary in Gaffney et al.'s (2007) scheme are less probable in theory because they involve convergent evolution of anatomically complex structures.

In conclusion, the results presented in this study and the previous discussion indicate that the peculiar pattern of ossification of the parasphenoid in turtles can explain at least the early stages of the evolution of the internal carotid complex in this group. However, further investigations are required in order to achieve a better understanding of the evolution of this complex, especially in meiolaniids and eucryptodires.

\section{Acknowledgements}

We wish to thank $\mathrm{C}$. Meyer and $\mathrm{B}$. Thüring $(\mathrm{MH}$, Switzerland) for access to the comparative collection at their institution, and for the permission to scan their specimen of Plesiochelys etalloni. J. Clack and M. Lowe (UMZC) granted access to the holotype of Mesochelys durlstonensis. G. Rougier (Louisville), D. Pol (Trelew), F. Witzmann, L. Tsuji (both Berlin) and R. Reisz (Toronto) are thanked for helpful discussions. Comments by reviewers D. Brinkman and W. G. Joyce and the editorial work of J. Greenough greatly improved the paper. This study was partially supported by a MINCYT (Argentina) and DAAD (Germany) fellowship to JS, a DFG grant to JM (Mu 1760/2-3), a postdoctoral grant from the Simone and Cino del Duca Foundation to JA (2008 Prize awarded to P. Janvier), and a CONICET-CNRS international cooperation grant for ANPCYT PICT 1756.

\section{References}

Bellairs, A. d'A., and Kamal, A.M. 1981. The chondrocranium and the development of the skull in recent reptiles. In Biology of Reptilia, Volume 11, Morphology F. Edited by C. Gans and T.S. Parsons. Academic Press, London. pp. 1-263.

Brinkman, D. B., and Nicholls, E.L. 1993. The skull of Neurankylus eximius (Testudines: Baenidae) and a reinterpretation of the relationships of this taxon. Journal of Vertebrate Paleontology, 13: 273-281.

Brinkman, D.B., and Peng, J.-H. 1993. New material of Sinemys (Testudines, Sinemydidae) from the Early Cretaceous of China. Canadian Journal of Earth Sciences, 30: 2139-2152.

de Beer, G.R. 1937. The development of the Vertebrate skull. Clarendon Press, Oxford. Evans, J., and Kemp, T.S. 1975. The cranial morphology of a new Lower Cretaceous turtle from Southern England. Palaeontology, 18: $25-40$.

Gaffney, E.S. 1975. A taxonomic revision of the Jurassic turtles Portlandemys and Plesiochelys. American Museum Novitates, 2574: 1-15.

Gaffney, E.S. 1976. Cranial morphology of the European Jurassic turtles Portlandemys and Plesiochelys. Bulletin of the American Museum of Natural History, 157: 487-544.

Gaffney, E.S. 1979a. Comparative cranial morphology of Recent and fossil turtles. Bulletin of the American Museum of Natural History, 164: 65-376.

Gaffney, E.S. 1979b. The Jurassic turtles from North America. Bulletin of the American Museum of Natural History, 162: 91-136.

Gaffney, E. S. 1983. The cranial morphology of the extinct horned turtle Meiolania platyceps, from the Pleistocene of Lord Howe Island, Australia. Bulletin of the American Museum of Natural History, 175: 361-480.

Gaffney, E.S. 1985. The cervical and caudal vertebrae of the cryptodiran turtle, Meiolania platyceps, from the Pleistocene of Lord Howe Island, Australia. American Museum of Natural History, 2805: 1-22.

Gaffney, E.S. 1990. The comparative osteology of the Triassic turtle Proganochelys. Bulletin of the American Museum of Natural History, 194: 1-263. 
Gaffney, E.S. 1996. The postcranial morphology of Meiolania platyceps and a review of the Meiolaniidae. Bulletin of the American Museum of Natural History, 229: $1-165$.

Gaffney, E. S., and Meylan, P. A. 1988. A phylogeny of turtles. In The phylogeny and classification of the tetrapods. Vol. 1, Amphibians, reptiles, birds. Edited by J. Benton. Systematic Association, special volume, no. 35A. Clarendon Press, Oxford. pp. 157- 219.

Gaffney, E.S., and Meylan, P.A. 1992. The Transylvanian turtle: Kallokibotion, a primitive cryptodire of Cretaceous age. American Museum Novitates, 3040: 137.

Gaffney, E.S., Rich, T.H., Vickers- Rich, P., Constantine, A., Vacca, R., and Kool, L. 2007. Chubutemys, a new eucryptodiran turtle from the Early Cretaceous of Argentina, and the relationships of Meiolaniidae. American Museum Novitates, 3599: 1-35.

Gonçalves, D.R. 2003. Descrição morfológica do crânio e mandíbula de Stratiotosuchus maxhechti (Crocodylomorpha, Cretáceo Superior do Brasil) e seu posicionamento filogenético. M.Sc. thesis. Universidade Federal do Rio de Janeiro, Rio de Janeiro, Brazil.

Jamniczky, H.A., Brinkman, D.B., and Russell, A.P. 2006. Phylogenetic implications of turtle cranial circulation: a review. In Fossil turtle research, Vol. 1. Edited by I.G. Danilov and J.F. Parham. Russian Journal of Herpetology, 13(Suppl.): 84-92.

Jollie, M.T. 1957. The head skeleton of the chicken and remarks on the anatomy of this region in other birds. Journal of Morphology, 100: 389-436.

Joyce, W.G. 2007. Phylogenetic relationships of Mesozoic turtles. Bulletin of the Yale Peabody Museum, 48: 3-102.

Klembara, J. 1993. The parasphenoid and associated dermal structures of the parabasisphenoid of Alligator mississippiensis (Daudin, 1802). Palaeontographica Abteilung A, 228: 143-164.

Lapparent de Broin, F. de, de la Fuente, M.S., and Fernández, M.S. 2007. Notoemys laticentralis (Chelonii, Pleurodira), Late Jurassic of Argentina: new examination of the anatomical structures and comparisons. Revue de Paléobiologie, 26(1): 99-136

Ling, L.J. 1983. Tooth replacement in a new genus of procolophonid from the Early Triassic of China. Palaeontology 26(3): 567-583.

Milner, A.R. 2004. The turtles of the Purbeck Limestone Group of Dorset, Southern England. Palaeontology 47(6): 1441-1467.
O'Keefe, F.R. 2001. A cladistic analysis and taxonomic revision of the Plesiosauria (Reptilia: Sauropterygia). Acta Zoologica Fennica, 213: 1-63.

Pehrson, T. 1945. Some problems concerning the development of the skull of turtles. Acta Zoologica, 26: 157-184.

Rieppel, O. 1980. The skull of the Upper Jurassic cryptodire turtle, Thalassemys, with a reconsideration of the chelonian braincase. Palaeontographica Abteilung A, 171: 105- 140.

Rieppel, O. 1993. Patterns of diversity in the reptilian skull. In The Skull. Edited by J. Hanken and B.K. Hall. The University of Chicago Press, Chicago and London. pp. 344-390.

Sheil, C.A. 2003. Osteology and skeletal development of Apalone spinifera (Reptilia: Testudines: Trionychidae). Journal of Morphology, 256: 42-78.

Sheil, C.A. 2005. Skeletal development of Macrochelys temminckii (Reptilia: Testudines: Chelydridae). Journal of Morphology, 263: 71-106.

Sheil, C. A., and Greenbaum, E.. 2005. Reconsideration of skeletal development of Chelydra serpentina (Reptilia: Testudinata: Chelydridae): evidence for intraspecific variation. Journal of Zoology, 265: 235-267.

Shishkin, M.A. 1968. On the cranial arterial system of the Labyrinthodonts. Acta Zoologica, 49: 1-22.

Sterli, J., and de la Fuente, M.S. 2010. Anatomy of Condorchelys antiqua Sterli, 2008 and the origin of the modern jaw closure mechanism in turtles. Journal of Vertebrate Paleontology 30(2): 351-366.

Sterli, J., and Joyce, W.G. 2007. The cranial anatomy of the Early Jurassic turtle Kayentachelys aprix. Acta Palaeontologica Polonica, 52: 675-694.

Sukhanov, V.B. 2000. Mesozoic turtles of Middle and Central Asia. In The age of dinosaurs in Russia and Mongolia. Edited by M.J. Benton, M.A. Shishkin, D.M. Unwin and E.N. Kurochkin. Cambridge University Press, Cambridge. pp. 309-367.

Tong, H., Claude, J., Naksri, W., Suteethorn, V., Buffetaut, E., Khansubha, S., Wongko, K., and Yuangdetkla, P. 2009. Basilochelys macrobios n. gen. and n. sp., a large cryptodiran turtle from the Phu Kradung Formation (latest Jurassic-earliest Cretaceous) of the Khorat Plateau, NE Thailand. Geological Society, London, Special Publications, 315: 153-173. 